Association for Information Systems AIS Electronic Library (AISeL)

AMCIS 1999 Proceedings

Americas Conference on Information Systems

(AMCIS)

December 1999

\title{
Internet Courses, Mature Learners: Two Undervalued Market Segments
}

Elizabeth Towell

Carroll College

Lynn Neeley

Northern Illinois University

Follow this and additional works at: http://aisel.aisnet.org/amcis 1999

\section{Recommended Citation}

Towell, Elizabeth and Neeley, Lynn, "Internet Courses, Mature Learners: Two Undervalued Market Segments" (1999). AMCIS 1999 Proceedings. 333.

http://aisel.aisnet.org/amcis1999/333

This material is brought to you by the Americas Conference on Information Systems (AMCIS) at AIS Electronic Library (AISeL). It has been accepted for inclusion in AMCIS 1999 Proceedings by an authorized administrator of AIS Electronic Library (AISeL). For more information, please contact elibrary@aisnet.org. 


\title{
Internet Courses, Mature Learners:Two Undervalued Market Segments
}

\author{
Elizabeth Towell, Carroll College, etowell@carroll1.cc.edu \\ Lynn Neeley, Northern Illinois University, m60cln1@wpo.cso.niu.edu
}

\begin{abstract}
Use of the World Wide Web (WWW) for instruction has grown dramatically in the last two years. Almost every major university in the US has some distance education offering [1]. Increasing competition and shrinking resources within public institutions have accelerated the growth of this technological innovation. Recent press on the subject suggests, however, that "education at a distance" is meeting tremendous resistance in some corners [7],[8].

While academia grapples with delivery mechanisms for the product that they market, the market itself is changing. There seems to be an equally dramatic change occurring in the demographics of the learner population. Adults returning to education settings represent a rapidly growing educational market segment. Almost half of all post-secondary students are now working adults over 24 years of age [9]. Universities and their faculties have given this historically small segment little commitment in the past. For the most part, they continue to do little to accommodate the problems of a maturing post-secondary student population: managers with difficult travel schedules, disabled adults with physical challenges, parents with child care responsibilities, and adult children who have elder care demands.
\end{abstract}

Distance education can be compared to other innovations that have disrupted established organizations. Problems experienced by other organizations facing rapidly changing technologies and markets bear striking similarities to the problems faced by universities in dealing with Web-based instruction and the changing demographics in the student population. Solutions likewise can be found by looking at the history of various disruptive innovations and the strategies common to the survivors.

A framework provided by Clayton Christensen [2], based on the "innovators" dilemma" in several commercial organizations, provides a viewpoint for the authors' analysis. He proposes four recognizable environmental conditions for "disruptive technologies" which can be seen to apply to the advent of online education: 1) the potential market size and financial return for the disruptive technology is not known; 2) small niche markets aren't expected to solve the problems of large institutions who face increasing competition and shrinking resources; 3 ) the customers of and investors in the institutions will dictate the eventual use of the resources; and 4) over time, the basis for customer choice will include functionality, reliability, convenience, and price. In this paper, we portray distance education delivered via the WWW as a disruptive innovation and the mature learner as a disruptive consumer that can be combined into successful avenues for academic institutions. Four recommendations are made for a successful online education strategy.

\section{The Innovator's Dilemma}

Like most institutions, universities serve a market and like to keep track of their market performance. While sometimes resisting the use of the term "customer," educators are in the business of providing a product and they strive to be better than their competitors at supplying that product. Likewise, in most institutions, at some point, a new approach is introduced to providing a product. If the institution is a bookseller, the new approach may be the introduction of Web-based shopping. The response of the bookseller may be that this is not the business that they are in. Use of the Web is gimmicky and lies at the bottom of the market in terms of quality and margins. If the institution is a large statefunded university, the new approach may be Web-based teaching. The university decision-makers may also respond that this is not the business that they are in. Education belongs in the classroom.

Clayton Christensen [2] provides several examples of institutions facing such new approaches and technologies. One powerful example involves the story of steel minimills. Minimills produce cost-competitive molten steel from scrap steel. They are called minimills because the scale necessary to process scrap steel is significantly less than what is needed for an integrated mill to produce molten steel from iron ore.

The first products produced in minimills in the 1960's were of marginal quality. The only market for the minimill producers was for steel reinforcing bars ("rebars") which was at the bottom of the market in terms of quality, cost and margins. The big steel makers were not interested in the rebar market because, not only were the margins low, the price-driven customers were the least loyal. Time-tested managerial practices suggested continued aggressive investment in the premium end of the market, paying close attention to the mainstream customers. 
Minimills, however, had much different cost structures than the integrated mills. They had less equipment and therefore less depreciation expense. The minimills could usually sell all of their rebar simply by making a few phone calls so marketing costs were minimal. Finally, they had no research and development costs. Over a thirty year period, they were able to improve the quality of their steel and infiltrate markets other than rebar. The minimill market share increased from essentially zero in 1965 to $40 \%$ in 1995 and will probably account for half of all steel production by the turn of the century. Not one of the world's integrated steel companies has built a mill employing minimill technology, still certain that this is not the business that they are in.

The difficulty, of course, is how to improve the performance of established products and still recognize important disruptive technologies and markets. Disruptive technologies often result in worse product performance, at least in the near term. There are many examples of industries facing disruptive technologies like the integrated steel mills. The personal computer disrupted the larger computer manufacturers; transistors disrupted in the vacuum tube market, HMO's disrupted conventional health insurers, small off-road motorcycles disrupted the powerful over-the-road cycle manufacturers; and discount retailing disrupted the department stores.

Why do leading organizations frequently stumble when confronting disruptive technologies? Christensen develops three themes.

Over time, development strategies generally have a "northeastern pull." Resource allocation processes direct resources towards new product proposals that promise higher margins or larger markets. Organizational graphs and charts are expected to show better speed, capacity, throughput, profits, etc. over time. That is, performance plots are expected to be northeastern vectors. Organizations tend to ignore technologies that do not improve what is perceived as the most important attributes of product performance in light of customers' needs. Products' attributes and the customers' needs, however, are derived from a frame of reference involving past choices. Established organizations have a practiced capability of giving customers more and better versions of the same thing.

Most large organizations do not want to look downward at small, emerging markets. While most organizations seem to be very good at delivering more and better versions of the same thing, they seem to have a great deal of trouble with downward vision and mobility. It becomes increasingly difficult for larger, established organizations to enter small, radically different markets even if they are destined to become larger in the future.
This is not just a matter of bureaucracy or complacency. Companies build capabilities in their products based on historical choices about which problems should be solved and which should be avoided.

To address disruptive innovation, a different value network must be developed which changes strategies and cost structures. Christensen defines a value network as " - the context in which a firm identifies and responds to customers' needs, solves problems, procures input, reacts to competitors, and strives for profit." Many disruptive technologies are championed by new firms because of the inability of established organizations to change strategies and cost structures, not technologies.

There is much evidence that even the universities that are embracing online instruction are having trouble changing strategies and cost structures. Research suggests that models of instruction appropriate for the Web are sorely lacking. Universities and faculties are attempting to shoe old models for instruction onto the Web with suboptimal results [3]. Wolcott [10] warns that the culture of faculty rewards has not changed to accommodate faculty work in distance education.

\section{What History Teaches Us}

Will the classic university survive? Will the learners of tomorrow make different choices in terms of functionality, reliability, convenience, and price? Will half the educational market be lost to entrant cyberschools that better accommodate the new learner types and the necessary strategies for successful Web-based instruction? History teaches us that some established organizations are able to accomodate both sustaining technologies and disruptive technologies. By looking at those organizations that are successful, Christensen points the way for academic institutions that are wanting to explore distance education but are struggling with developing the necessary strategies and cost structures. Success-driven institutions can draw from his study involving hundreds of organizations facing disruptive technologies. His work provides four suggestions.

Develop and deliver distance education through projects where learners need it most. By the year 2001, more than 15 million adults are expected to be in the market for higher education. These students will also fill a wide range of other roles: employees, spouses, parents, citizens, community and church leaders, and adult care providers [6]. Their needs will define a very different educational market than has been seen in the past, namely that of the 18 to 22 year old, who has parent-financing, and lives in a dorm on campus. 
Many researchers suggests that finding the right match between students and programs will be the basis for viability of US institutions in the future ([4],[5]. Most distance education course currently offered, are online counterparts to traditional for-credit offerings. The new market will include demand for many additional offerings such as continuing education courses, refresher and retooling courses, and professional certification programs. Schools should search out distance education niches for the mature learner in which they can grow and survive.

Place these projects in organizational subunits that are small enough to get excited about small opportunities and small wins. Not only do schools need to find the right courses to offer, they need to empower the right people to select the appropriate technologies and create the right organizational structure to deliver the courses. The impetus for change must come from a group that is small and focused enough to short-circuit the debates over the value of the disruptive technology in light of the value of competencies previously cultivated.

The climate among faculty at large with regard to distance education is skeptical at best. Web-based courses do not seem to address the needs of the current customers, they promise the university little in terms of profit, and do not seem to enhance the career opportunities for talented academicians. The environment in which online instruction is executed should be controlled to the extent that everyone involved views success as crucial to their future and the future of the organization.

Plan to fail early and inexpensively searching for the proper market. Failure, in the economic sense, is inevitable when looking for initial applications for disruptive technologies. Measurement of success must be very different than success with a sustaining technology. We have a reasonably good idea of what we are looking for as outcomes in the traditional classroom setting. We are able to plan offerings, enrollments, and revenues.

Less is known about what an online market needs or how large the market will be. Early offerings may not be economical. Early adopters will fail to predict precisely how the new technology will be used and the size of the market. Success should be measured in terms of the new knowledge gained about new customers and applications.

Value the attributes of the disruptive product rather than looking for a breakthrough that will enable the disruptive product to compete in mainstream markets. The Web presents novel avenues to facilitate learning including opportunities to build collaborative learning teams and to encourage global communities [3]. Online instruction can provide "any where, any time education" for mature learners. It should not be seen to compete in the current market for professor-centered university instruction. Subunits, that are commissioned to define projects for the new technology, should value the attributes unique to the Web rather than focusing on the capabilities that are missing.

\section{References}

[1] Bothun, G.D. "Distance Education:Effective Learning or Content Free Credits?" Cause/Effect, 21:2, 1998, pp. 28-37.

[2] Christensen, C. The Innovator's Dilemma, Havard Business School Press, Boston, MA, 1997.

[3] Duchastel, P.A. "A Web-Based Model for University Instruction," Journal Educational Technology Systems, 25:3, 1996-1997, pp.221-228.

[4] Lucas, R. "An Ecology of Distance Learning," Syllabus, 11:10, 1998, pp. 14-22.

[5] Mowen, A.J. and Parks, S. C. "Competitive Marketing of Distance Education: A Model for Placing Quality Within a Strategic Planning Context, The American Journal of Distance Education, 11:3, 1997, pp. 27-40.

[6] Neeley, L., Niemi, J. A., and Ehrhard, B. J. "Classes Going the Distance So People Don't Have To: Instructional Opportunities for Adult Learners," T.H.E. Journal, 26:4, 1998, pp. 72-74.

[7] Noble, D. F., "Digital Diploma Mills: The Automation of Higher Education," $f ; ® s \dagger-m \not \tilde{n} d @ ¥$ (peer reviewed journal on the Internet), 3:1, 1998, http://firstmonday.dk/issues/issue3_1/noble/index.html.

[8] Noble, D. F., "Digital Diploma Mills, Part III, The Bloom is Off the Rose," Distributed through the Red Rock Eater News Service, December, 1998, http://commons.somewhere.com/rre/1998/RRE.Digital.Di ploma.Mill.html.

[9] Stamps, D. "The For-Profit Future of Higher Education," Training, August, 1998, pp. 23-29.

[10] Wolcott, L. L. "Tenure, Promotion, and Distance Education: Examining the Culture of Faculty Rewards," The American Journal of Distance Education, 11:2, 1997, pp. 3-18. 